\title{
A Novel Model for Evaluating the Flow of Endodontic Materials Using Micro-computed Tomography
}

\author{
Mario Tanomaru-Filbo, PbD, Fernanda Ferrari Esteves Torres, MSc, Roberta Bosso-Martelo, PbD, \\ Gisselle Moraima Chávez-Andrade, MSc, Idomeo Bonetti-Filbo, PbD, \\ and Juliane Maria Guerreiro-Tanomaru, PbD
}

\begin{abstract}
Ahstract
Introduction: Flow and filling ability are important properties of endodontic materials. The aim of this study was to propose a new technique for evaluating flow using micro-computed tomographic $(\mu \mathrm{CT})$ imaging. Methods: A glass plate was manufactured with a central cavity and 4 grooves extending out horizontally and vertically. The flow of MTA-Angelus (Angelus, Londrina, PR, Brazil), zinc oxide eugenol (ZOE), and Biodentine (BIO) (Septodont, Saint Maur des Fossés, France) was evaluated using International Standards Organization (ISO) 6876/2002 and a new technique as follows: $0.05 \pm 0.005 \mathrm{~mL}$ of each material was placed in the central cavity, and another glass plate and metal weight with a total mass of $120 \mathrm{~g}$ were placed over the material. The plate/material set was scanned using $\mu \mathrm{CT}$ imaging. The flow was calculated by linear measurement $(\mathrm{mm})$ of the material in the grooves. Central cavity filling was calculated in $\mathrm{mm}^{3}$ in the central cavity. Lateral cavity filling (LCF) was measured by LCF mean values up to $2 \mathrm{~mm}$ from the central cavity. Data were analyzed statistically using analysis of variance and Tukey tests with a $5 \%$ significance level. Results: ZOE showed the highest flow rate determined by ISO methodology $(P<.05)$. Analysis performed using $\mu \mathrm{CT}$ imaging showed MTA-Angelus and ZOE had higher linear flow rates in the grooves. Central cavity filling was similar for the materials. However, LCF was higher for BIO versus ZOE. Conclusions: Although ZOE presented better flow determined by ISO methodology, BIO showed the best filling ability. The model of the technique proposed for evaluating flow using $\mu \mathrm{CT}$ imaging showed proper and reproducible results and could improve flow analysis. (J Endod 2017;43:796-800)
\end{abstract}

\section{Key Words}

Endodontics, micro-computed tomography, physicochemical properties
$T_{0}^{\text {hetions }}$ he flow ability of endodontic materials is important for filling the root canal systems or the retrograde cavity $(1,2)$. Endodontic cement flow is evaluated in accordance with ISO Standard 6876/ 2002 (3). There is no specific standard for evaluating root-end filling or reparative materials; therefore, the flow of materials such as mineral trioxide aggregate (MTA) and reparative materials has been evaluated using the ISO standard (4-6). The sealing ability of a sealer is related to certain physical properties, such as flow and volumetric setting shrinkage (7), and these properties may be different between cements and reparative materials.

Furthermore, because the ISO standard (3) uses linear measurements, it offers no correlation with the filling ability of the materials (8). Models for evaluating the ability of endodontic sealers to penetrate dentinal tubules using confocal laser microscopy have been proposed $(9,10)$, but they are not easily reproducible methods. Micro-computed tomographic $(\mu \mathrm{CT})$ imaging has been used for evaluating the filling ability provided by different filling techniques and filling materials (11-14). This makes it a proper alternative tool for analyzing the property of flow and filling provided by different materials by means of filling volume.

MTA is a calcium silicate biomaterial with various indications that include root perforation treatment and retrograde filling (15-19). MTA is biocompatible and induces mineral tissue formation $(20,21)$. However, MTA is difficult to manipulate and insert into cavities because of its consistency (22). Biodentine (BIO) (Septodont, Saint Maur des Fossés, France) is a calcium silicate-based reparative cement with indications similar to those of MTA (23-28) and has additives in its formulation (29) to improve its cavity filling ability.

Although there is no standardized ISO method to evaluate the flow of reparative materials such as MTA, methods that allow 3-dimensional evaluation of this property using $\mu \mathrm{CT}$ imaging may be an alternative. This study proposes a new technique for evaluating the flow of endodontic materials using $\mu \mathrm{CT}$ imaging in comparison with the conventional tests recommended by ISO (3).

From the Department of Restorative Dentistry, Araraquara Dental School, São Paulo State University, Araraquara, São Paulo, Brazil.

Address requests for reprints to Dr Mario Tanomaru-Filho, Department of Restorative Dentistry, Araraquara Dental School, São Paulo State University-UNESP, Humaitá Street 1680, 14801-903 Araraquara, SP, Brazil. E-mail address: tanomaru@uol.com.br

0099-2399/\$ - see front matter

Copyright (C) 2017 American Association of Endodontists.

http://dx.doi.org/10.1016/j.joen.2016.12.002 


\section{Material and Methods}

The materials evaluated and proportions used are described in Table 1.

\section{Flow}

The flow test was conducted in accordance with ISO Standard 6876 (3). After manipulation of the cement, $0.05 \mathrm{~mL}$ of the material was placed in the center of a glass plate using a graduated syringe $(n=10)$. At $180 \pm 5$ seconds after initiating the manipulation, another glass plate $(20 \mathrm{~g})$ was placed on the plate with the cement, and a 100-g weight was put on the top plate and kept there for 10 minutes. After this period, the maximum and minimum diameters of the material on the glass plate were measured. When a difference of less than $1 \mathrm{~mm}$ between the diameters was observed, the mean value was recorded. A second evaluation was made by photographing the material on the plate alongside a millimeter ruler. The images obtained were evaluated using the Image Tool version 3.0 program (The University of Texas Health Science Center, San Antonio, TX) to obtain the area of flow of the material expressed in $\mathrm{mm}^{2}$ according to Tanomaru-Filho et al (30).

\section{Technique Proposed for Analyzing Flow by Means of $\mu$ CT Imaging}

A glass plate was fabricated with a central cavity $(1 \times 1 \times 2 \mathrm{~mm}$ [length, width, and height]). Grooves of equal size were made in the cavity, extending out $12 \mathrm{~mm}$ horizontally and vertically to the 4 sides. Preliminary tests were performed to define the dimensions to be used, compatible with the flow of the amount of material to be used. The amount of material was based on the ISO Standard 6876 (3) flow test. An amount of $0.05 \pm 0.005 \mathrm{~mL}$ of each material was placed in the central cavity, and another glass $(20 \mathrm{~g})$ and metal weight $(100 \mathrm{~g})$ with a total mass of $120 \mathrm{~g}$ were placed on the materials (Fig. 1) and kept there for 10 minutes. After completion of the initial setting time, the materials were scanned individually. Scanning was performed by $\mu \mathrm{CT}$ imaging (SkyScan 1176; Bruker-microCT, Kontich, Belgium) and completed using 90-kV X-ray tube voltages and a $278-\mu$ A anode current, a copper filter of $0.1 \mathrm{~mm}$, an isotropic voxel of $9 \mu \mathrm{m}$, and an evolution cycle of $360^{\circ}$. The linear flow $(\mathrm{mm})$ measurement of the material on each side of the grooves (horizontal and vertical) was analyzed. The mean of the 4 measurements was considered the linear flow for each evaluation. The filling in volume $\left(\mathrm{mm}^{3}\right)$ of the materials in the central area $(1 \times 1 \times 2 \mathrm{~mm}$ [length, width, and height]) was determined as the central cavity filling. The filling in volume $\left(\mathrm{mm}^{3}\right)$ of the materials in the lateral areas was determined up to $2 \mathrm{~mm}$ for each side of the central cavity. The means of the 4 measurements was considered the lateral cavity filling for each analysis (Fig. 2). Reconstruction of the images was performed using NRecon software (V1.6.10.4, Bruker-microCT). The correction parameters of smoothing beam hardening and ring artifacts were defined indi-

TABLE 1. Root-end Filling Materials, Manufacturers, and Proportions Used

\begin{tabular}{|c|c|}
\hline Material & Manufacturer \\
\hline MTA-Angelus & $\begin{array}{c}\text { MTA; Angelus, Londrina, Brazil } \\
\text { Proportion: } 1 \mathrm{~g} \text { powder to } 0.33 \mathrm{~mL} \\
\text { distilled water }\end{array}$ \\
\hline Biodentine & $\begin{array}{c}\text { Septodont, Saint Maur des Fossés, France } \\
\text { Proportion: } 1 \mathrm{~g} \text { powder to } 6 \text { drops } \\
\text { of liquid }\end{array}$ \\
\hline $\begin{array}{l}\text { Zinc oxide } \\
\quad \text { and eugenol }\end{array}$ & $\begin{array}{c}\text { SS White Art. Dent. Ltda., Rio de Janeiro, } \\
\text { RJ, Brazil } \\
\text { Proportion: } \begin{array}{c}1 \mathrm{~g} \text { zinc oxide to } 0.2 \mathrm{~mL} \\
\text { eugenol }\end{array}\end{array}$ \\
\hline
\end{tabular}

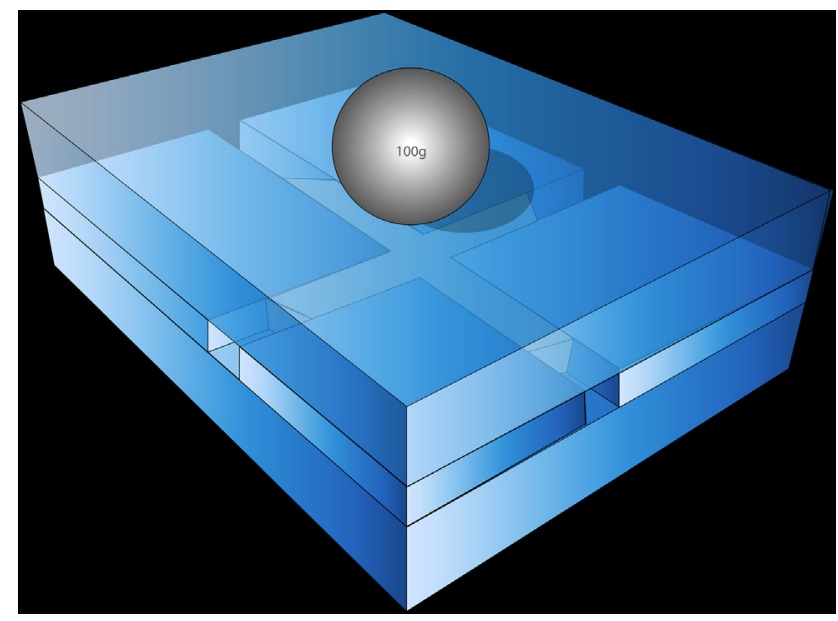

Figure 1. A view representing the set formed by the glass plates, endodontic material, and metal weight.

vidually for each material. The reconstructed images were saved in the coronal, sagittal, and transaxial planes in the Data Viewer program (V1.5.2.4; Bruker-microCT). The images were analyzed using CTAn software (V1.15, Bruker-microCT) (Fig. 3), and 3-dimensional models of the materials' after flow within the grooves were created 3-dimensionally using CTVol (V2.0; Bruker-microCT) software (Fig. 4).

\section{Statistical Analysis}

The data obtained were analyzed statistically using analysis of variance and the Tukey test with a significance level of $5 \%$.

\section{Conventional Flow Test}

\section{Results}

The results of the flow test $(\mathrm{mm})$ for both linear and area $\left(\mathrm{mm}^{2}\right)$ values are represented in Table 2. Zinc oxide eugenol (ZOE) was the material that showed the highest linear and area $\left(\mathrm{mm}^{2}\right)$ flow rates $(P<.05)$.

\section{Flow Test Using $\mu$ CT Imaging}

The flow test results using $\mu$ CT imaging are shown in Table 3. MTA and ZOE presented the highest linear rates $(P<.05)$. Volumetric filling in the central cavity was similar for all the materials $(P>.05)$. However, the filling volume in the lateral direction was the highest for BIO compared with ZOE $(P<.05)$.

\section{Discussion}

This article describes a novel model for evaluating flow using $\mu \mathrm{CT}$ imaging. Analysis of volume $\left(\mathrm{mm}^{3}\right)$ based on $\mu \mathrm{CT}$ images allowed evaluation of the filling ability in the central and lateral areas after placing the material between glass plates. Accordingly, these volumetric data correspond to the ability of the material to fill a space and to flow into the lateral spaces, an important property for an endodontic cement or root-end filling material. The device proposed allowed standardization of the quantity of material and of the pressure to be put on the material during the test, similar to that proposed by the ISO standards (3). Because there is no standard for assessing the flow of repair cements, this test would provide information on the flow and filling of materials in 3 dimensions. Furthermore, the flow of the material undergoing condensation contributes to the filling of spaces, as in a 


\section{Basic Research-Technology}

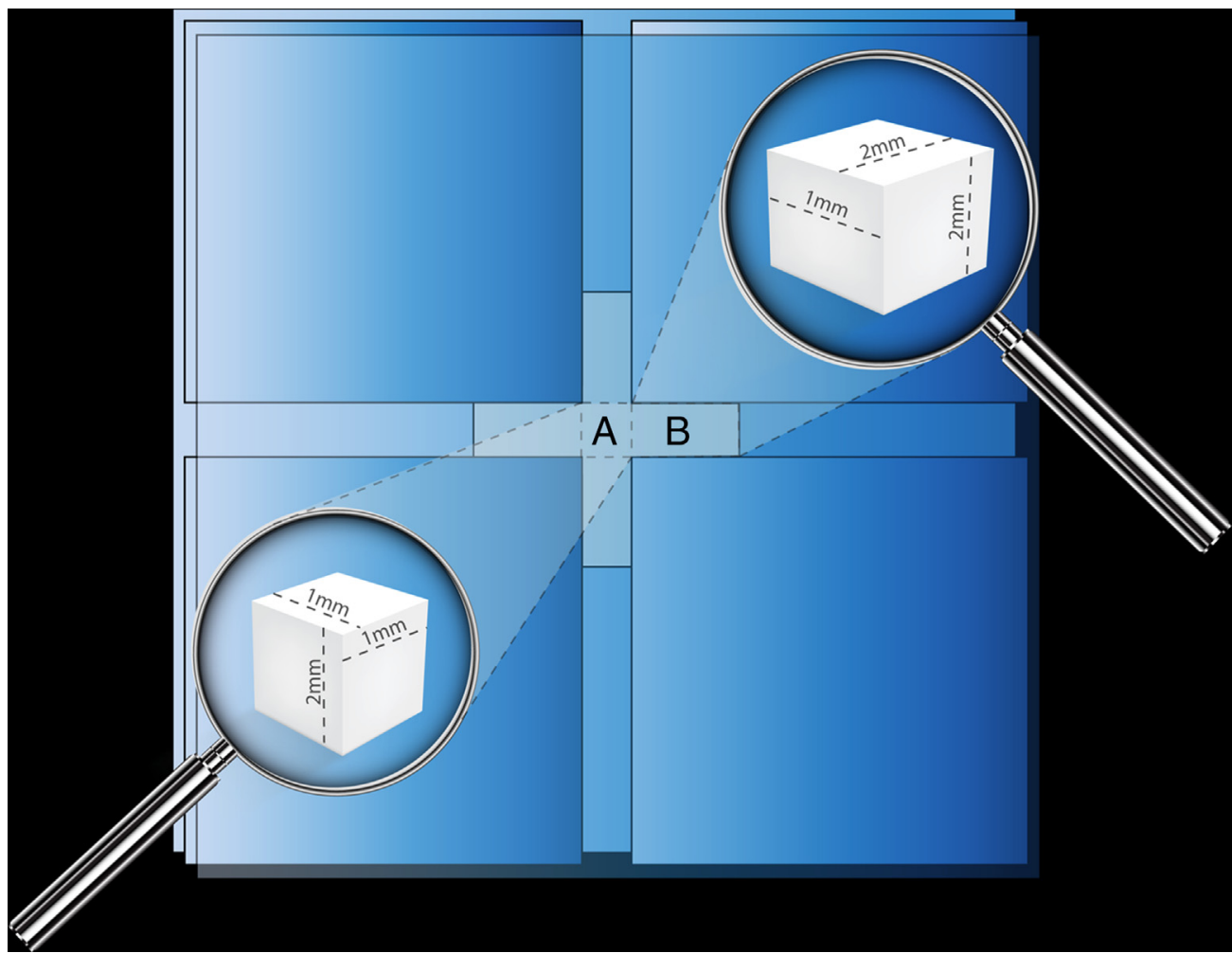

Figure 2. An illustration of the areas evaluated using CTAn software. (A) Central cavity filling and $(B)$ lateral cavity filling $2 \mathrm{~mm}$ from the central area in each groove.

retrograde cavity. Thus, the proposed test contributes to the selection of the most appropriate material according to its clinical application.

The flow of endodontic materials may favor filling and sealing ability (6). The flow observed for MTA-Angelus (Angelus, Londrina, PR,
Brazil) is in agreement with Tanomaru-Filho et al (6), as determined by conventional methodology, and with Camilleri (5), who evaluated white ProRoot MTA (Dentsply, Tulsa, OK) using ISO Standard 6876/ 2002 (3). MTA presents a low flow and reduced workability, thus making the material not indicated as a root canal filling material (22).

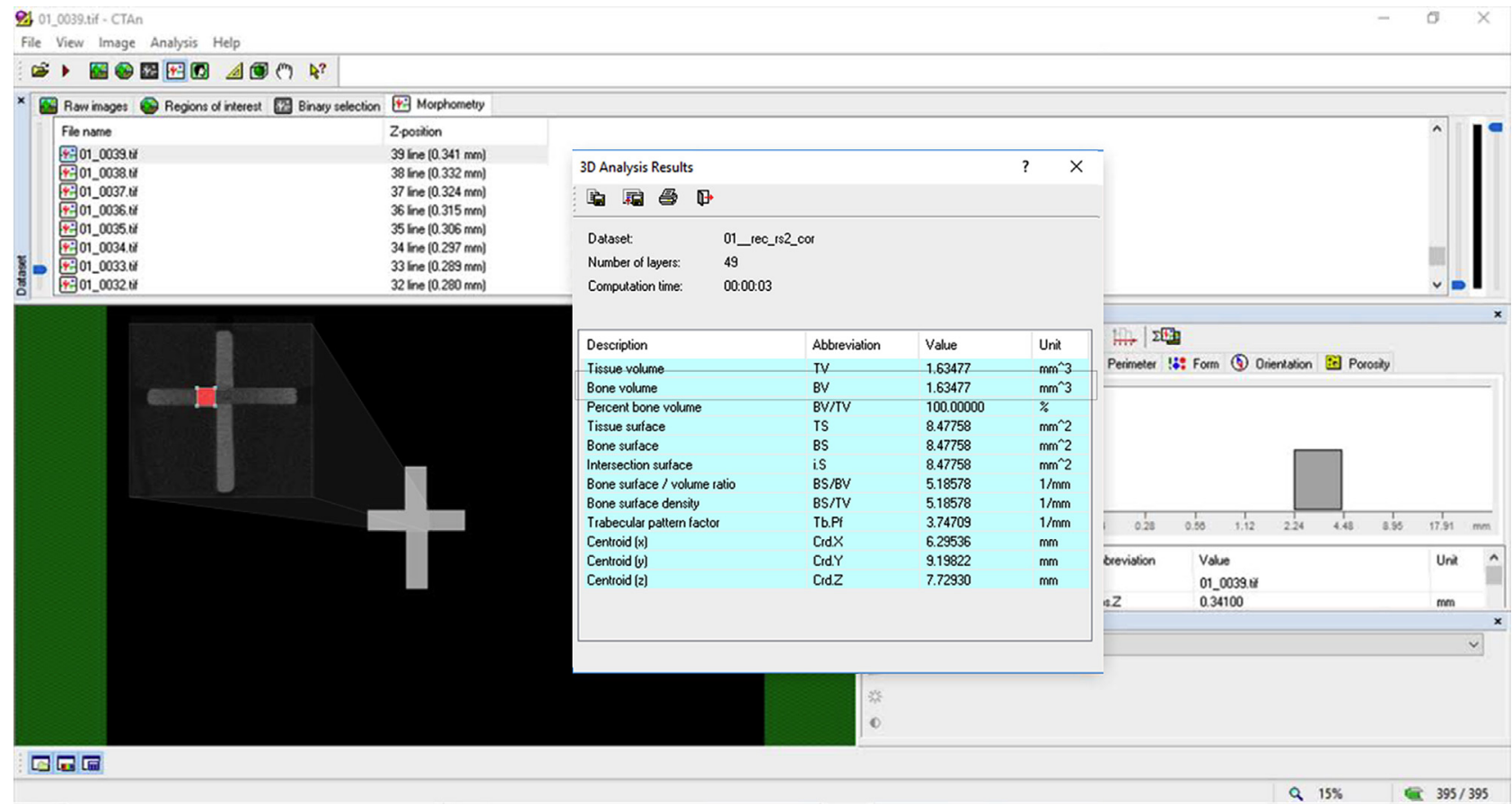

Figure 3. Evaluation of lateral cavity filling using CTAn software. 


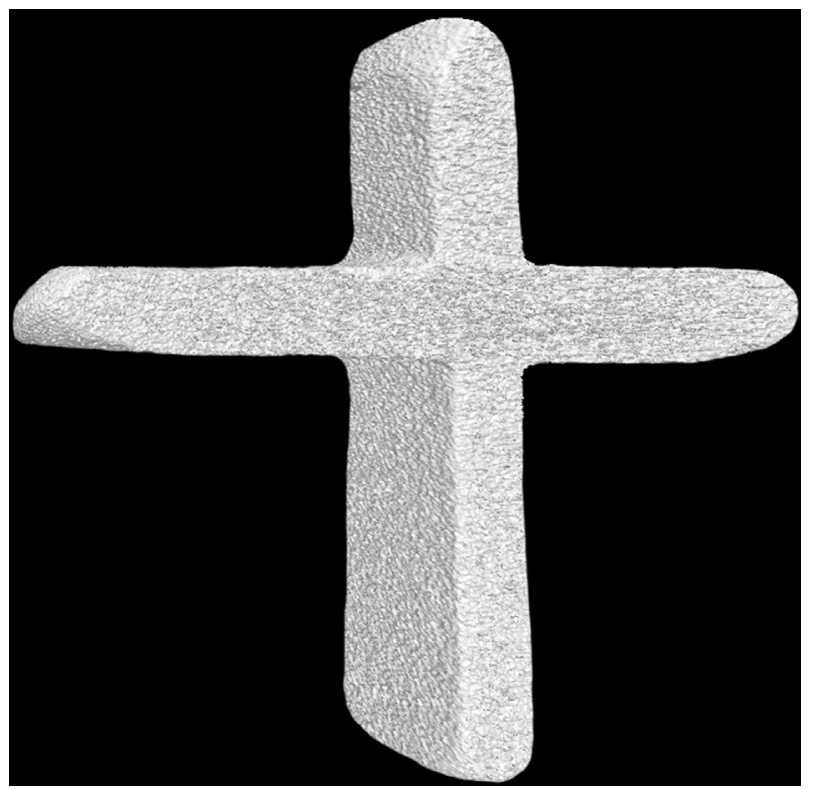

Figure 4. A model after material flow inside the grooves reconstructed in 3 dimensions using CTVol software.

The conventional test showed that ZOE has a higher linear flow rate. Tanomaru-Filho et al (6) evaluated the flow of root-end filling materials using a linear measurement, in accordance with ISO Standard 6876-2002, and an additional parameter based on area. They observed a flow of $6.37 \mathrm{~mm}( \pm 0.47)$ and $32.36 \mathrm{~mm}^{2}( \pm 5.7)$ for MTA-Angelus, which is similar to that of the present study. However, $\mu$ CT evaluation showed that MTA and ZOE had the highest linear flow rate. Central cavity filling was similar for all the materials. However, the filling volume in the lateral direction was highest for BIO in comparison with ZOE. Based on these results, the authors suggest that the flow capacity assessed by conventional tests does not present a direct correlation with the filling ability of the material, especially considering filling in the lateral direction.

Butt et al (29) observed that BIO and MTA-Angelus promoted proper apical sealing. However, BIO showed more consistency after manipulation, possibly leading to the better filling ability observed in the present study. Koubi et al (31) evaluated the marginal integrity of restorations performed with BIO and observed a reduced particle size of the cement, which may be associated with better penetrability of the material (10), and a small expansion of the material, factors that may have contributed to the improved filling ability of this material in the present study.

The results of the present study suggest that flow and filling are not directly proportional. Thus, a material with better ability to flow linearly will not necessarily provide greater filling space. Furthermore, the use of $\mu \mathrm{CT}$ imaging as a model for this evaluation may be appropriate, considering that it reduced the variability of the data obtained (32).

The authors concluded that although ZOE presented better flow determined by ISO methodology, BIO showed the best filling ability.

TABLE 2. Mean and Standard Deviation of the Flow Results of Root-end Filling Materials Evaluated in Accordance with ISO Standard 6876/2002

\begin{tabular}{lccc}
\hline Test/Material & MTA-Angelus & Biodentine & $\begin{array}{c}\text { Zinc oxide } \\
\text { eugenol }\end{array}$ \\
\hline Flow (mm) & $6.29 \pm 0.41^{\mathrm{b}}$ & $6.51 \pm 0.60^{\mathrm{b}}$ & $9.01 \pm 0.69^{\mathrm{a}}$ \\
Flow (area-mm $\left.\mathrm{mm}^{2}\right)$ & $31.34 \pm 4.99^{\mathrm{b}}$ & $42.93 \pm 7.54^{\mathrm{b}}$ & $73.01 \pm 20.74^{\mathrm{a}}$ \\
\hline
\end{tabular}

Different letters in the same row indicate a statistically significant difference.
TABLE 3. Mean and Standard Deviation of the Flow Results of Root-end Filling Materials Evaluated by Micro-computed Tomographic Imaging

\begin{tabular}{lccc}
\hline Test/Material & MTA-Angelus & Biodentine & $\begin{array}{c}\text { Zinc oxide } \\
\text { eugenol }\end{array}$ \\
\hline Flow $(\mathrm{mm})$ & $10.14 \pm 2.37^{\mathrm{a}}$ & $7.25 \pm 1.14^{\mathrm{b}}$ & $11.51 \pm 1.15^{\mathrm{a}}$ \\
Central cavity & $1.58 \pm 0.16^{\mathrm{a}}$ & $1.62 \pm 0.13^{\mathrm{a}}$ & $1.52 \pm 0.15^{\mathrm{a}}$ \\
$\quad$ filling $\left(\mathrm{mm}^{3}\right)$ & & & \\
$\begin{array}{c}\text { Lateral cavity } \\
\text { filling }\left(\mathrm{mm}^{3}\right)\end{array}$ & $1.42 \pm 0.14^{\mathrm{a}, \mathrm{b}}$ & $1.50 \pm 0.13^{\mathrm{a}}$ & $1.37 \pm 0.12^{\mathrm{b}}$ \\
\hline
\end{tabular}

Different letters in the same row indicate a statistically significant difference.

The technique proposed for evaluating the flow by means of $\mu \mathrm{CT}$ imaging showed proper and reproducible results and could improve flow analysis.

\section{Acknowledgments}

This work was supported by FAPESP (2014/16510-0, 2015/ 03437-6 and 2016/00321-0).

The authors deny any conflicts of interest related to this study.

\section{References}

1. Duarte MA, Ordinola-Zapata R, Bernardes RA, et al. Influence of calcium hydroxide association on the physical properties of AH Plus. J Endod 2010;36: $1048-51$.

2. Zicari F, Couthino E, De Munck J, et al. Bonding effectiveness and sealing ability of fiber-post bonding. Dent Mater 2008;24:967-77.

3. International Organization for Standardization Dentistry (ISO). ISO 6876. Root canal sealing materials. London, UK:: British Standards Institution; 2002.

4. Asgary S, Shahabi S, Jafarzadeh T, et al. The properties of a new endodontic material. J Endod 2008;34:990-3.

5. Camilleri J. Evaluation of selected properties of mineral trioxide aggregate sealer cement. J Endod 2009:35:1412-7.

6. Tanomaru-Filho M, Garcia AC, Bosso-Martelo R, et al. Influence of addition of calcium oxide on physicochemical properties of Portland cement with zirconium or niobium oxide. J Conserv Dent 2015;18:105-8.

7. Wu MK, De Gee AJ, Wesselink PR. Leakage of four root canal sealers at different thickness. Int Endod J 1994;27:304-8.

8. Almeida JF, Gomes BP, Ferraz CC, et al. Filling of artificial lateral canals and microleakage and flow of five endodontic sealers. Int Endod J 2007;40:692-9.

9. Kuci A, Alacam T, Yavas 0, et al. Sealer penetration into dentinal tubules in the presence or absence of smear layer: a confocal laser scanning microscopic study. J Endod 2014;40:1627-31.

10. McMichael GE, Primus CM, Opperman LA. Dentinal tubule penetration of tricalcium silicate sealers. J Endod 2016;42:632-6.

11. Celikten B, F Uzuntas C, I Orhan A, et al. Micro-CT assessment of the sealing ability of three root canal filling techniques. J Oral Sci 2015;57:361-6.

12. Keles A, Alcin H, Kamalak A, Versiani MA. Micro-CT evaluation of root filling quality in oval-shaped canals. Int Endod J 2014;47:1177-84.

13. Moeller L, Wenzel A, Wegge-Larsen AM, et al. Quality of root fillings performed with two root filling techniques. An in vitro study using micro-CT. Acta Odontol Scand 2013;71:689-96.

14. Somma F, Cretella G, Carotenuto M, et al. Quality of thermoplasticized and single point root fillings assessed by micro-computed tomography. Int Endod J 2011; 44:362-9.

15. Massi S, Tanomaru-Filho M, Silva GF, et al. pH, calcium ion release, and setting time of an experimental mineral trioxide aggregate-based root canal sealer. J Endod 2011;37:844-6.

16. Nekoofar MH, Davies TE, Stone D, et al. Microstructure and chemical analysis of blood-contaminated mineral trioxide aggregate. Int Endod J 2011;44:1011-8.

17. Santos AD, Moraes JC, Araujo EB, et al. Physico-chemical properties of MTA and a novel experimental cement. Int Endod J 2005;38:443-7.

18. Tsurumachi T. Current strategy for successful periradicular surgery. J Oral Sci 2013; 55:267-73.

19. Jacobovitz M, Vianna ME, Pandolfelli VC, et al. Root canal filling with cements based on mineral aggregates: an in vitro analysis of bacterial microleakage. Oral Surg Oral Med Oral Pathol Oral Radiol Endod 2009;108:140-4.

20. Tanomaru JM, Tanomaru-Filho M, Hotta J, et al. Antimicrobial activity of endodontic sealers based on calcium hydroxide and MTA. Acta Odontol Latinoam 2008;21:147-51. 


\section{Basic Research-Technology}

21. Tanomaru-Filho M, Luis MR, Leonardo MR, et al. Evaluation of periapical repair following retrograde filling with different root-end filling materials in dog teeth with periapical lesions. Oral Surg Oral Med Oral Pathol Oral Radiol Endod 2006; 102:127-32.

22. Canadas PS, Berastegui E, Gaton-Hernandez P, et al. Physicochemical properties and interfacial adaptation of root canal sealers. Braz Dent J 2014;25:435-41.

23. Koubi G, Colon P, Franquin JC, et al. Clinical evaluation of the performance and safety of a new dentine substitute, Biodentine, in the restoration of posterior teeth - a prospective study. Clin Oral Investig 2013;17:243-9.

24. Laurent P, Camps J, About I. Biodentine(TM) induces TGF-beta1 release from human pulp cells and early dental pulp mineralization. Int Endod J 2012;45:439-48.

25. Laurent $\mathrm{P}$, Camps J, De Meo M, et al. Induction of specific cell responses to a $\mathrm{Ca}(3)$ $\mathrm{SiO}$ (5)-based posterior restorative material. Dent Mater 2008;24:1486-94.

26. Raskin A, Eschrich G, Dejou J, About I. In vitro microleakage of Biodentine as a dentin substitute compared to Fuji II LC in cervical lining restorations. J Adhes Dent 2012;14:535-42.
27. Tran XV, Gorin C, Willig C, et al. Effect of a calcium-silicate-based restorative cement on pulp repair. J Dent Res 2012;91:1166-71.

28. Zanini M, Sautier JM, Berdal A, Simon S. Biodentine induces immortalized murine pulp cell differentiation into odontoblast-like cells and stimulates biomineralization. J Endod 2012;38:1220-6.

29. Butt N, Talwar S, Chaudhry S, et al. Comparison of physical and mechanical properties of mineral trioxide aggregate and Biodentine. Indian J Dent Res 2014;25: $692-7$.

30. Tanomaru-Filho M, Bier CA, Tanomaru JM, Barros DB. Evaluation of the thermoplasticity of different gutta-percha cones and the TC system. J Appl Oral Sci 2007; 15:131-4.

31. Koubi S, Elmerini H, Koubi G, et al. Quantitative evaluation by glucose diffusion of microleakage in aged calcium silicate-based open-sandwich restorations. Int J Dent 2012;2012:105863

32. Brito-Junior M, Leoni GB, Pereira RD, et al. A novel dentin push-out bond strength model that uses micro-computed tomography. J Endod 2015;41:2058-63. 